\title{
Resilience in the First Episode of Major Depressive Disorder
}

\author{
Toshihiko Maekawa1 ${ }^{1,2 *}$, Shingo Souda ${ }^{2}$, Katsura Oyakawa ${ }^{2}$, Mutsuhide Tanaka1, Takao Yamasaki ${ }^{1}$ \\ ${ }^{1}$ Department of Clinical Neurophysiology, Faculty of Medical Sciences, Kyushu University, Fukuoka, Japan \\ ${ }^{2}$ Department of Psychiatry, Amekudai Hospital, Tenjinkai Medical Corporation, Naha, Japan \\ Email: *t-mae@npsych.med.kyushu-u.ac.jp
}

How to cite this paper: Maekawa, T., Souda, S., Oyakawa, K., Tanaka, M. and Yamasaki, T. (2017) Resilience in the First Episode of Major Depressive Disorder. Open Journal of Medical Psychology, 6, 115-125. https://doi.org/10.4236/ojmp.2017.62009

Received: March 17, 2017

Accepted: April 18, 2017

Published: April 21, 2017

Copyright (c) 2017 by authors and Scientific Research Publishing Inc. This work is licensed under the Creative Commons Attribution International License (CC BY 4.0).

http://creativecommons.org/licenses/by/4.0/

Open Access

\begin{abstract}
Aim: Resilience refers to the human ability to adapt to tragedy, trauma, adversity, and significant stressors. Recently, resilience has been defined as a potentially modifiable factor that can be improved through intervention. Here, we examined resilience during a 3-month period as patients experienced their first episode of major depressive disorder (MDD). We hypothesized that despite MDD, resilient people could recover from depressive states more quickly than less resilient people. Methods: Twelve patients experienced their first MDD episode and 21 healthy control individuals participated in the study. Data from the Hamilton Depression Rating Scale (HAM-D), S-H Resilience Scale (S-HRS), and State-Trait Anxiety Index (STAI) were collected at two time points. Time 1 was the first visit after registration and Time 2 was 12 weeks later. Based on the symptoms described by the HAM-D results, the MDD group was divided into MDD-remission and MDD-residual subgroups. Results: Compared with controls, patients showed significantly lower resilience (low scores for Factor-A, Factor-B, and total S-HRS). Moreover, total SHRS scores for the MDD-remission group increased significantly from the Time 1 to Time 2, while those in MDD-residual group did not change. No significant differences in STAI scores were observed between MDD-remission and MDD-residual groups at either time point. Conclusion: This is the first report to show that patients experiencing their first episode of MDD show low resilience, and that a resilience scale might be a good index for estimating recovery from depression.
\end{abstract}

\section{Keywords}

Major Depressive Disorder, Self-Efficacy, S-H Resilience Scale, Social Support, State-Trait Anxiety Index 


\section{Introduction}

Major depressive disorder (MDD) is characterized by mood disturbances and can present as low mood, loss of pleasure, or irritability, and is one of the most frequent psychiatric disorders in the community and in psychiatric settings [1]. In 2011, The World Health Organization reported that depressive disorders were estimated to be the second leading cause of years lived with disability [2]. Several studies have shown that MDD is a heterogeneous syndrome [3] [4] with many different presentations and possibly different risk factors for individual symptoms [5] [6]. Environmental factors, such as sexual, physical, or emotional abuse during childhood, as well as economic problems, are associated with the risk of developing MDD [7]. Genetic factors also contribute to the risk of stress exposure, and stressful social events can serve as triggers for epigenetic alterations at specific gene loci [8], potentially causing long-term changes in brain functioning [9]. Personal traits are also a key factor underlying this disorder. For all these reasons, no established mechanism can explain all aspects of the disease.

Resilience refers to the human ability, which involves not only personal trait but also social support and utility of it, to adapt to tragedy, trauma, adversity, and significant stressors. This is a dynamic process that is influenced by life events and challenges [10]. According to Wells et al. [11], resilience comprises three groups of attribute pairs: competence and adversity, resources and risks, and protection processes and vulnerability. Most have viewed resilience as a stress-coping ability in the face of adversity. Various positive features of mental health, such as the characteristics of resilient people, have been reported [12], and the clinical significance of resilience has received considerable research attention [13] [14]. For example, coping self-efficacy, which is the belief in one's own ability to manage posttraumatic recovery demands, has been shown to be an important predictor of psychological adjustment to a variety of traumas [15]. Additionally, positive aspects of mental health, such as optimism, vigor, and selfconfidence have been shown to be better indicators of remission than the absence of depressive symptoms [16]. Recently, resilience has been identified as a factor [17] that can be improved through intervention [18].

While there have been several literature mentioned about resilience in depressive state [19], most of them were subject to model animals or healthy community. They have shown that early-life stress, including abuse, neglect, and exposure to inter-parental violence, influences affective and cognitive function, and is associated with a higher risk of developing depression [20]. Animal research has shown that the amount of care received in the first few days of life determines behavioral, hormonal, and neurochemical aspects of stress responses [21]. The concepts of resilience and vulnerability arise from the observation that individuals vary considerably in their responses to adverse environmental conditions [22]. In line with these notions, (perhaps some researchers think it is obvious) we hypothesized that resilient people can recover from depressive states more quickly than non-resilient people, even if they experience MDD. We tested this hypothesis by measuring the resilience of patients during a 3-month period as 
they were experiencing their first episode of MDD, and comparing it between groups with different degrees of recovery.

\section{Methods}

\subsection{Participants and Procedures}

Twelve patients who were in the midst of their first episode of MDD and 21 healthy controls (HCs) participated in the study. All participants were aged 19 65 years. The exclusion criteria were: (i) neurological illness or major head trauma that could result in abnormal neuroimaging findings; (ii) an additional mental illness (aside from MDD); (iii) alcohol or drug dependence during the participant's life time; (iv) alcohol or drug abuse within the past 5 years; and (v) a verbal intelligence quotient below 75 . Healthy controls were screened using the Structured Clinical Interview for DSM-IV (SCID), non-patient edition. None of the healthy controls or their first-degree relatives had any Axis-I psychiatric disorders [23]. The study was approved by the Kyushu University Hospital Institutional Review Board for Clinical Trials and all participants gave their informed consent after receiving a complete description of the study.

All patients were recruited from Amekudai Hospital, and were diagnosed with MDD based on the SCID for DSM-IV Axis-I disorders and the patient's medical records [24]. Two senior clinical psychiatrists confirmed that all participants had the ability to consent to participate in the experiment. Data were collected between April 2015 and January 2016 at two time points for each participant: Time 1 was the first visit after registration and Time 2 was a follow-up visit 12 weeks later.

\subsection{Assessment Instruments}

\subsubsection{Hamilton Depression Rating Scale (HAM-D)}

The severity of depression was assessed using the HAM-D, a standard measure that has been included in most studies of depression [25]. Although the brevity of the HAM-D can be beneficial, coverage of symptoms is limited and some symptoms currently viewed as relevant to the concept of depression are omitted (e.g., hypersomnia and pessimism). The HAM-D contains 17 items pertaining to symptoms of depression experienced over the preceding week. A score of $0-7$ is generally accepted as within the normal range (or in clinical remission), while 20 or higher indicates at least moderate severity [26]. Here, we used a HAM-D inclusion threshold of at least 14 points.

\subsubsection{S-H Resilience Scale (S-HRS)}

While several scales measure resilience [27], the S-HRS part 1 was used herein to measure the participant's resilience. In Japan, the S-HRS is one of the most common resilience-measuring tests; it is widespread commercially, not only for clinical but also non-clinical uses. This scale was developed by Sukemune et al. for Japanese adults and its high validity and reliability in "social support" ( $\alpha=$ $0.85)$, "self-efficacy" ( $\alpha=0.81)$, and "sociality" ( $\alpha=0.77)$ have been confirmed 
[28] [29]. Assessment of these three categories was based on the scores for "Factor-A", "Factor-B", and "Factor-C", respectively. Moreover, total scores of the S-HRS are indicated in the participant's overall resilience. The self-reported questionnaire consisted of 27 items: Nine questions for each of the three factors. Lower scores indicate less resilience.

\subsubsection{State-Trait Anxiety Index (STAI)}

The STAI was used to assess anxiety. STAI is a self-administered, 40-item questionnaire consisting of two parts (the state [S] and the trait [T]), which was first introduced in the 1970s, and revised in 1983 [30]. One of its advantages is the ability to differentiate a present state of anxiety (STAI-s; 20 items) from longstanding trait anxiety (STAI-t; 20 items). Scores range from 20 to 80, with higher scores indicating greater anxiety. STAI also one of the most popular anxiety inventories for clinical and non-clinical applications in the world.

\subsection{Statistical Analyses}

All statistical analysis was performed using IBM SPSS Statistics for Windows (IBM Corp., Released 2012, IBM SPSS Statistics for Windows, version 21.0. Armonk, NY, USA: IBM Corp.). First, the S-HRS scores for the MDD group were compared with those for the HC group using a two tailed independent t-test. Then, the MDD group was divided into two subgroups based on their HAM-D scores: the symptom-remission group $(n=5$, HAM-D score $\leq 8$ at Time 2; MDD-remission) and the symptom-residual group $(n=5$, HAM-D score $>8$ at Time 2; MDD-residual). The S-HRS and STAI scores at Time 1 and Time 2 were compared for each subgroup using a paired t-test.

\section{Results}

\subsection{Demographic Characteristics}

Ten of the 12 patients completed the study, while two withdrew before completion. Although those two patients did not appear at Time 2, their data for Time 1 were analyzed, which allowed us to compare differences of resilience between MDD patients and HC groups. Demographic characteristics of the participants are shown in Table 1 . There were no significant differences in sex, age, or years

Table 1. Demographic and clinical characteristics of the study participants.

\begin{tabular}{ccc}
\hline Characteristic & MDD $(\mathrm{n}=10)$ & HC $(\mathrm{n}=21)$ \\
\cline { 2 - 3 } & Mean (SD) & Mean (SD) \\
\hline Sex, female:male & $3: 7$ & $9: 12$ \\
Age, $y$ & $48.3(11.4)$ & $46.5(11.3)$ \\
Education, $y$ & $15.2(3.0)$ & NA \\
Months from onset of illness & $6.7(5.3)$ & NA \\
Imipramine equivalent, mg & $130(114.5)$ & NA \\
HAM-D score & $16.1(5.5)$ &
\end{tabular}

Abbreviations: MDD: major depressive disorder; HC: healthy control; HAM-D: Hamilton Depression Rating Scale; NA: not available. 
of education between groups. Seven patients were receiving antidepressants and seven were receiving drugs in the benzodiazepine family. That is, four patients took both antidepressants and benzodiazepine family drugs.

\subsection{Assessments}

The inclusion threshold for the HAM-D was at least 14 points. The mean \pm SD for the HAM-D scores of all MDD patients at Time 1 was $16.1 \pm 5.5$. At Time 2, HAM-D scores for the MDD-remission and MDD-residual groups were $4.2 \pm$ 2.4 and $15.2 \pm 3.7$, respectively. At Time 1 , independent $\mathrm{t}$-tests revealed that Factor-A ( $\mathrm{p}<0.0001)$, Factor-B ( $\mathrm{p}<0.001)$, and total S-HRS score $(\mathrm{p}<0.0001)$ were significantly lower in the MDD group than is the HC group (Figure 1). We hypothesized that resilient people recover from a depressive state faster than not-resilient ones. Therefore, we next looked at changes in symptoms over time within the MDD group. A paired t-test revealed that total S-HRS score was significantly higher in the MDD-remission group at Time 2 than at Time $1(\mathrm{p}<$ 0.05 ), while this effect was not observed in the MDD-residual group (Figure 2). No statistical differences in STAI scores were observed between MDD-remission and MDD-residual groups at either time point (Figure 3).

\section{Discussion}

The present study examined resilience of patients during their first episode of MDD. Compared with non-depressed participants, these patients showed significantly lower resilience as determined by the S-HRS, especially in "social support" and "self-efficacy". Moreover, total S-HRS score significantly increased between Time 1 and Time 2 in the MDD-remission group, but not in the MDDresidual group. Regarding STAI, we found no significant difference in score between the MDD-remission and MDD-residual groups at either time point.

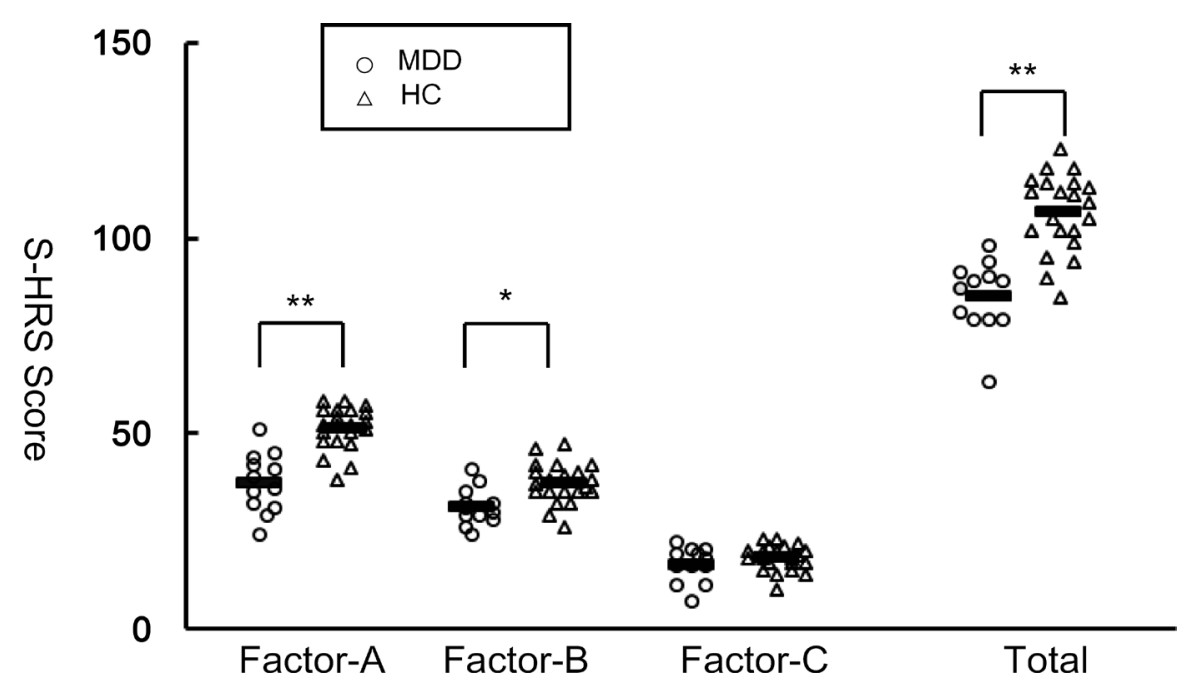

Figure 1. S-H Resilience Scale (S-HRS) scores for patients with major depressive disorder (MDD) and healthy controls (HC) at Time 1.Circles, MDD group. Triangles, HC group. Black bars, group means. Mean scores for Factor-A, Factor-B, and total S-HRS score were significantly lower in the MDD group than in the HC group. ${ }^{*}, \mathrm{p}<0.001,{ }^{* *}, \mathrm{p}<0.0001$. 


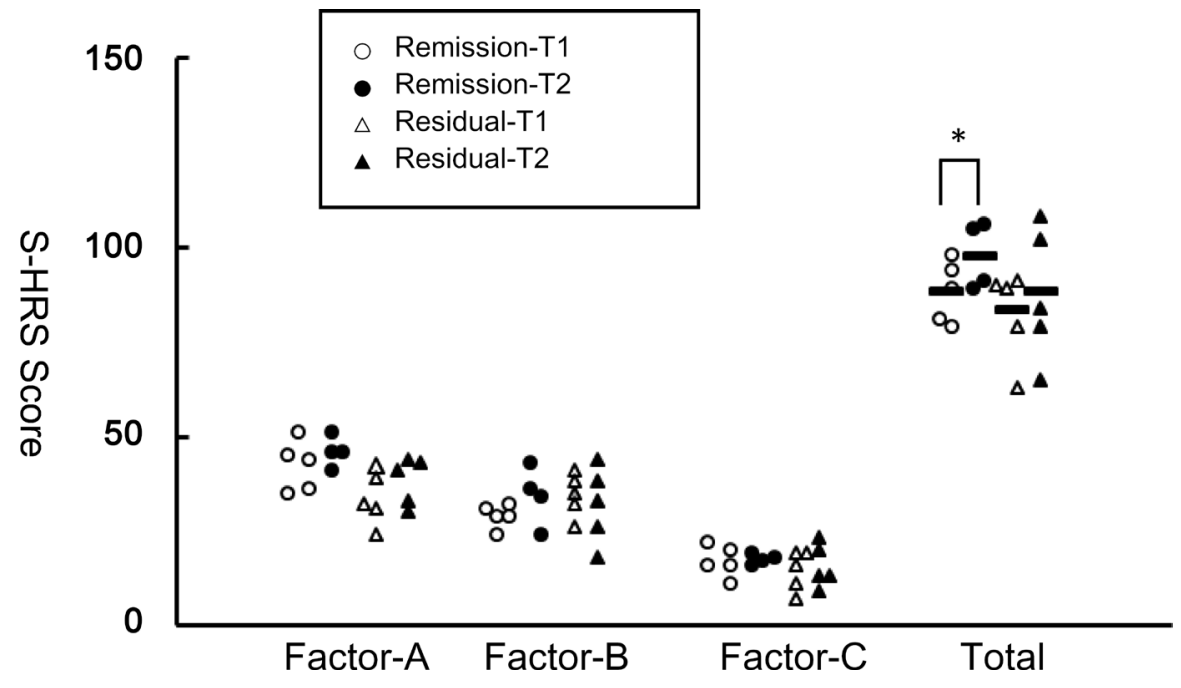

Figure 2. S-H Resilience Scale (S-HRS) scores for the MDD-remission and MDD-residual subgroups at Time 1 and Time 2. Circles, MDD-remission group. Triangles, MDD-residual group. Black fill, Time 1. White fill, Time 2. Total S-HRS score for the MDD-residual group increased significantly between Time 1 and Time $2 .{ }^{*}, \mathrm{p}<0.05$.

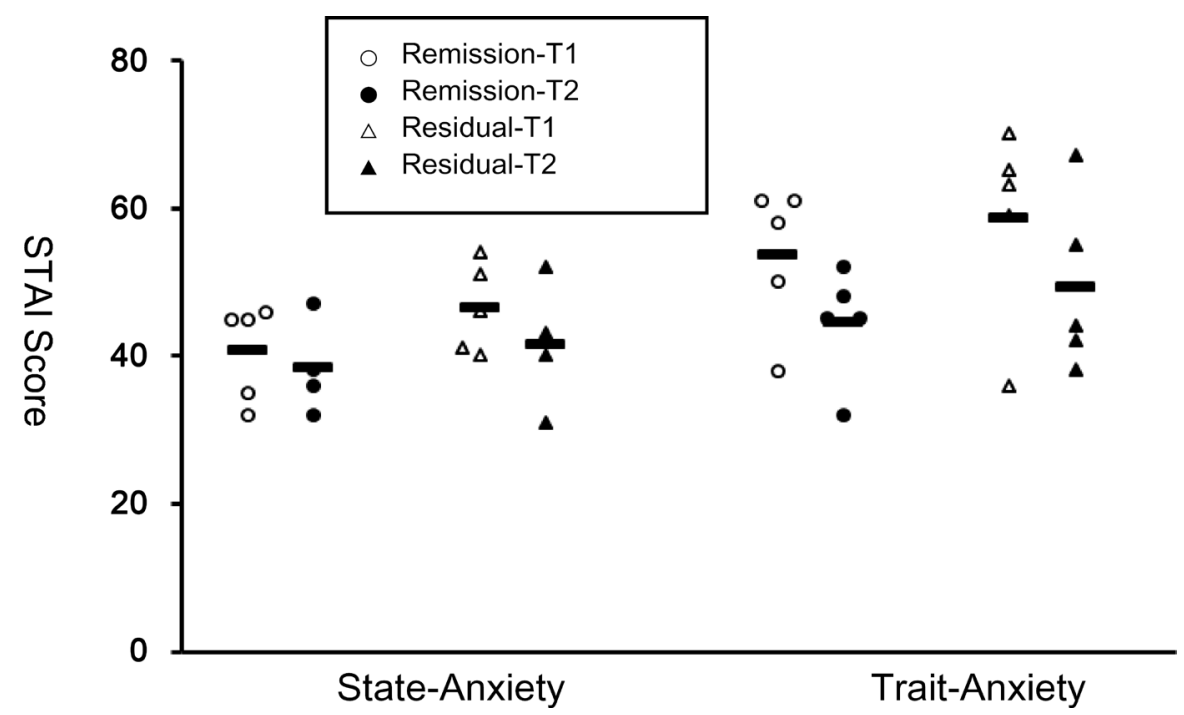

Figure 3. State-Trait Anxiety Index (STAI) scores for the MDD-remission and MDD-residual groups at Time 1 and Time 2. No statistical differences between groups were found at either time point.

\subsection{Resilience in Patients with MDD}

Although depressed patients might be generally less severely impaired in their everyday lives than patients with other mental disorders, such as autism and schizophrenia [31] [32], the impairment of social functioning, defined as "an individual's ability to perform and fulfil normal social roles," is considered a key sign of depression [33]. Dysfunction in social interactions remains persistent even 3 years after recovery from depressive symptoms [34] and is correlated with unemployment, disability and decreased work performance [35]. Further, the interpersonal difficulties might result from reduced motivation, altered empathic responding in social interactions, and reduced capacity to produce effective so- 
lutions for interpersonal problems. Additionally, lack of expressiveness in the nonverbal behavior of depressed individuals, such as reduced tendency to smile [36], is likely to be interpreted as impolite, uninterested, or inattentive by dyadic partners attempting to interact with them. Resilient people are well equipped to manage mental crises using not only their own abilities but also social interaction.

In the present study, compared with control participants, patients with MDD showed significantly lower resilience for Factor-A, Factor-B, and total S-HRS score. Factor-A and Factor-B represent "social support" and "self-efficacy", respectively [28], which allow us to infer that the patients in the present study could not make good use of social support offered by others and did not feel that they could resolve their problems successfully by themselves. In terms of Factor-C ("sociality"), scores did not differ significantly between the MDD and control groups. Patients appear to have felt that they managed their social relationships with others well. Hence, we believe that this resilience scale is a tool for assessing the social resources of patients with MDD and their ability to utilize them.

\subsection{Resilience and Recovery from Depression}

Within the MDD group, total S-HRS score for the MDD-remission group increased significantly between Time 1 and Time 2, while that for the MDD-residual group did not. Although this study had several limitations (small sample size, insufficient sample control, and a short observation period), these findings are important because literature on resilience in MDD is scarce. Moreover, most studies have targeted experimental animals or healthy people. Shirotani et al. collected data for the S-HRS and the Self-rating Depression Scale (SDS) [19] from 40 depressive patients (20 MDD, 6 bipolar depression, 5 adjustment disorder, 3 anxiety disorder and 5 others) at the beginning and end of a 3-month period. They found that the total S-HRS score significantly differs between the patients and controls at the first time point. Additionally, SDS and total S-HRS scores were inversely correlated. These findings are consistent with the result of the present study in which S-HRS scores increased in the MDD-remission group but not in the MDD-residual group. Therefore, total S-HRS score is a potentially good index of progress in recovering from depression.

\subsection{Resilience and Anxiety}

Anxiety and depressive disorders commonly occur alone, but often occur together [37]. Depressive and anxiety disorders have among the highest rates of comorbidity of all categories of psychiatric diagnostics [38]. Their comorbidity is particularly striking in rates of current co-occurrence: $45 \%$ - $67 \%$ of individuals diagnosed with MDD meet criteria for at least one concurrent anxiety disorder. One study showed resilience was negatively associated with both anxiety and depressive disorders, which was reasonable because a resilient outcome implies healthy functioning [39]. However, most literature has shown inconsistent find- 
ings of positive, negative, and absent relationships [40]. In the present study, patients' STAI scores did not change between Time 1 and Time 2, suggesting STAI was not sensitive to resiliency in the MDD patients. Theoretically, resilience comprises social support, self-efficacy, and sociality, which means it is not simply an index of personal traits. Patients in the present study may show high resiliency even when kept at a state of high anxiety. Further work is needed to elucidate the relationship between resilience and anxiety.

\subsection{Methodological Reservations}

This study has several limitations. First, we could not exclude the effects of antidepressant or neuroleptic medication. Cross-sectional studies with a more homogenous patient group (drug-free vs. medicated), as well as studies assessing participants before and after treatment with specific medications, are required in future. Second, the sample size was small and observation period short. Though statistical analyses showed meaning effects, we still think the results of this study were preliminary. Therefore, it makes in-depth interpretation of the results for the subcategory analyses difficult.

\section{Conclusion}

To the best of our knowledge, the current study is the first to show that patients experiencing their first MDD episode show low resilience, especially in the factors of "social support" and "self-efficacy." Additionally, total resilience-scale scores might be a good index for progress in recovery from depression and be very helpful for prevention and cure of MDD.

\section{Acknowledgements}

We appreciate Dr. Naoki Taira M.D. and Dr. Masahito Taira M.D. for their cooperation with participant registration. This work was supported by JSPS KAKENHI Grant numbers JP15K09833 and JP26560295.

\section{References}

[1] Kessler, R.C., Berglund, P., Demler, O., Jin, R. and Walters, E.E. (2005) Lifetime Prevalence and Age-of-Onset Distributions' of DSM-IV Disorders in the National Comorbidity Survey Replication. Archives of General Psychiatry, 62, 593-602. https://doi.org/10.1001/archpsyc.62.6.593

[2] Ferrari, A.J., Charlson, F.J., Norman, R.E., et al. (2013) Burden of Depressive Disorders by Country, Sex, Age, and Year: Findings from the Global Burden of Disease Study 2010. PLoS Medicine, 10, e1001547. https://doi.org/10.1371/journal.pmed.1001547

[3] Rush, A.J., Trivedi, M.H., Wisniewski, S.R., et al. (2006) Acute and Longer-Term Outcomes in Depressed Outpatients Requiring One or Several Treatment Steps: A STAR ${ }^{\star}$ D Report. The American Journal of Psychiatry, 163, 1905-1917. https://doi.org/10.1176/ajp.2006.163.11.1905

[4] Harald, B. and Gordon, P. (2012) Meta-Review of Depressive Subtyping Models. Journal of Affective Disorders, 139, 126-140. https://doi.org/10.1016/j.jad.2011.07.015 
[5] Fried, E.I., Nesse, R.M., Zivin, K., Guille, C. and Sen, S. (2014) Depression Is More than the Sum Score of Its Parts: Individual DSM Symptoms Have Different Risk Factors. Psychological Medicine, 44, 2067-2076. https://doi.org/10.1017/S0033291713002900

[6] Kendler, K.S., Aggen, S.H. and Neale, M.C. (2013) Evidence for Multiple Genetic Factors Underlying DSM-IV Criteria for Major Depression. JAMA Psychiatry, 70, 599-607. https://doi.org/10.1001/jamapsychiatry.2013.751

[7] Otte, C., Gold, S.M., Penninx, B.W., et al. (2016) Major Depressive Disorder. Nature Reviews Disease Primers, 2, Article No. 16065. https://doi.org/10.1038/nrdp.2016.65

[8] Kendler, K.S., Hettema, J.M., Butera, F., Gardner, C.O. and Prescott, C.A. (2003) Life Event Dimensions of Loss, Humiliation, Entrapment, and Danger in the Prediction of Onsets of Major Depression and Generalized Anxiety. Archives of General Psychiatry, 60, 789-796. https://doi.org/10.1001/archpsyc.60.8.789

[9] Lohoff, F.W. (2010) Overview of the Genetics of Major Depressive Disorder. Current Psychiatry Reports, 12, 539-546. https://doi.org/10.1007/s11920-010-0150-6

[10] Wermelinger Ávila, M.P., Lucchetti, A.L.G. and Lucchetti, G. (2017) Association between Depression and Resilience in Older Adults: A Systematic Review and MetaAnalysis. International Journal of Geriatric Psychiatry, 32, 237-246. https://doi.org/10.1002/gps.4619

[11] Wells, M., Avers, D. and Brooks, G. (2012) Resilience, Physical Performance Measures, and Self-Perceived Physical and Mental Health in Older Catholic Nuns. Journal of Geriatric Physical Therapy, 35, 126-131.

https://doi.org/10.1519/JPT.0b013e318237103f

[12] Rutter, M. (1985) Resilience in the Face of Adversity. Protective Factors and Resistance to Psychiatric Disorder. The British Journal of Psychiatry, 147, 598-611. https://doi.org/10.1192/bjp.147.6.598

[13] Fancourt, D., Perkins, R., Ascenso, S., et al. (2016) Effects of Group Drumming Interventions on Anxiety, Depression, Social Resilience and Inflammatory Immune Response among Mental Health Service Users. PLoS ONE, 11, e0151136. https://doi.org/10.1371/journal.pone.0151136

[14] Alschuler, K.N., Kratz, A.L. and Ehde, D.M. (2016) Resilience and Vulnerability in Individuals with Chronic Pain and Physical Disability. Rehabilitation Psychology, 61, 7-18. https://doi.org/10.1037/rep0000055

[15] Benight, C.C. and Bandura, A. (2004) Social Cognitive Theory of Posttraumatic Recovery: The Role of Perceived Self-Efficacy. Behaviour Research and Therapy, 42, 1129-1148.

[16] Zimmerman, M., McGlinchey, J.B., Posternak, M.A., et al. (2006) How Should Remission from Depression Be Defined? The Depressed Patient's Perspective. The American Journal of Psychiatry, 163, 148-150. https://doi.org/10.1176/appi.ajp.163.1.148

[17] Hoge, E.A., Austin, E.D. and Pollack, M.H. (2007) Resilience: Research Evidence and Conceptual Considerations for Posttraumatic Stress Disorder. Depression and Anxiety, 24, 139-152. https://doi.org/10.1002/da.20175

[18] Connor, K.M. (2006) Assessment of Resilience in the Aftermath of Trauma. The Journal of Clinical Psychiatry, 67, 46-49.

[19] Shirotani, K., Nakano, A. and Saito, T. (2013) Role of Resilience in Recovery Process from Depressive State: A Study Subject to Patients in the Department of Psychosomatic Medicine. The Japanese Journal of Clinical Psychiatry, 42, 899-907. (In Japanese)

[20] Seok, J.H., Lee, K.U., Kim, W., et al. (2012) Impact of Early-Life Stress and Resi- 
lience on Patients with Major Depressive Disorder. Yonsei Medical Journal, 53, 1093-1098. https://doi.org/10.3349/ymj.2012.53.6.1093

[21] Silveira, P.P., Portella, A.K., da Silva Benetti, C., et al. (2011) Association between $\mathrm{Na}^{+}, \mathrm{K}^{+}$-ATPase Activity and the Vulnerability/Resilience to Mood Disorders Induced by Early Life Experience. Neurochemical Research, 36, 2075-2082.

https://doi.org/10.1007/s11064-011-0531-1

[22] Carli, V., Mandelli, L., Zaninotto, L., et al. (2011) A Protective Genetic Variant for Adverse Environments? The Role of Childhood Traumas and Serotonin Transporter Gene on Resilience and Depressive Severity in a High-Risk Population. European Psychiatry, 26, 471-478. https://doi.org/10.1016/j.eurpsy.2011.04.008

[23] First, M.B., Spitzer, R.L., Gibbon, M., et al. (1995) The Structured Clinical Interview for DSM-III-R Personality Disorders (SCID-II). Part II: Multi-Site Test-Retest Reliability Study. Journal of Personality Disorders, 9, 92-104.

https://doi.org/10.1521/pedi.1995.9.2.92

[24] First, M.B., Spitzer, R.L., Gibbon, M. and Williams, J.B. (2002) Structured Clinical Interview for DSM-IV-TR Axis I Disorders, Research Version, Patient Edition. (SCID-I/P) Biometrics Research, New York State Psychiatric Institute, New York.

[25] Endicott, J., Cohen, J., Nee, J., Fleiss, J. and Sarantakos, S. (1981) Hamilton Depression Rating-Scale: Extracted from Regular and Change Versions of the Schedule for Affective-Disorders and Schizophrenia. Archives of General Psychiatry, 38, 98-103. https://doi.org/10.1001/archpsyc.1981.01780260100011

[26] Hamilton, M. (1960) A Rating Scale for Depression. Journal of Neurology, Neurosurgery, and Psychiatry, 23, 56-62. https://doi.org/10.1136/jnnp.23.1.56

[27] Windle, G., Bennett, K.M. and Noyes, J. (2011) A Methodological Review of Resilience Measurement Scales. Health and Quality of Life Outcomes, 9, 8. https://doi.org/10.1186/1477-7525-9-8

[28] Sukemune, S. (2007) S-H Style Resilience Test. Takei Industrial Co. Ltd. (In Japanese)

[29] Sato, T. and Sukemune, S. (2009) A Trail of Standarizing Resilience Scale-A Study of Development, Reliability, and Validity of "S-H Resilience Test (Part 1)". The Japanese Nursing Research, 42, 5-52. (In Japanese)

[30] Julian, L.J. (2011) Measures of Anxiety: State-Trait Anxiety Inventory (STAI), Beck Anxiety Inventory (BAI), and Hospital Anxiety and Depression Scale-Anxiety (HADS-A). Arthritis Care \& Research, 63, S467-S472. https://doi.org/10.1002/acr.20561

[31] Bazin, N., Brunet-Gouet, E., Bourdet, C., et al. (2009) Quantitative Assessment of Attribution of Intentions to Others in Schizophrenia Using an Ecological VideoBased Task: A Comparison with Manic and Depressed Patients. Psychiatry Research, 167, 28-35. https://doi.org/10.1016/j.psychres.2007.12.010

[32] Derntl, B. and Habel, U. (2011) Deficits in Social Cognition: A Marker for Psychiatric Disorders? European Archives of Psychiatry and Clinical Neuroscience, 26, 145. https://doi.org/10.1007/s00406-011-0244-0

[33] Hirschfeld, R.M., Montgomery, S.A., Keller, M.B., et al. (2000) Social Functioning in Depression: A Review. The Journal of Clinical Psychiatry, 61, 268-275. https://doi.org/10.4088/JCP.v61n0405

[34] Rhebergen, D., Beekman, A.T.F., de Graaf, R., et al. (2010) Trajectories of Recovery of Social and Physical Functioning in Major Depression, Dysthymic Disorder and Double Depression: A 3-Year Follow-Up. Journal of Affective Disorders, 124, 148 156. https://doi.org/10.1016/j.jad.2009.10.029 
[35] Rizvi, S.J., Cyriac, A., Grima, E., et al. (2015) Depression and Employment Status in Primary and Tertiary Care Settings. The Canadian Journal of Psychiatry, 60, 14-22. https://doi.org/10.1177/070674371506000105

[36] Rehman, U.S., Gollan, J. and Mortimer, A.R. (2008) The Marital Context of Depression: Research, Limitations, and New Directions. Clinical Psychology Review, 28, 179-198.

[37] Merikangas, K.R., Nakamura, E.F. and Kessler, R.C. (2009) Epidemiology of Mental Disorders in Children and Adolescents. Dialogues in Clinical Neuroscience, 11, 720.

[38] Kessler, R.C., Chiu, W., Demler, O. and Walters, E.E. (2005) Prevalence, Severity, and Comorbidity of 12-Month DSM-IV Disorders in the National Comorbidity Survey Replication. Archives of General Psychiatry, 62, 617-627.

https://doi.org/10.1001/archpsyc.62.6.617

[39] Scali, J., Gandubert, C., Ritchie, K., et al. (2012) Measuring Resilience in Adult Women Using the 10-Items Connor-Davidson Resilience Scale (CD-RISC). Role of Trauma Exposure and Anxiety Disorders. PLoS ONE, 7, e39879. https://doi.org/10.1371/journal.pone.0039879

[40] Westphal, M. and Bonanno, G.A. (2007) Posttraumatic Growth and Resilience to Trauma: Different Sides of the Same Coin or Different Coins? Applied Psychology, 56, 417-427. https://doi.org/10.1111/j.1464-0597.2007.00298.x

\section{Scientific Research Publishing}

Submit or recommend next manuscript to SCIRP and we will provide best service for you:

Accepting pre-submission inquiries through Email, Facebook, LinkedIn, Twitter, etc. A wide selection of journals (inclusive of 9 subjects, more than 200 journals) Providing 24-hour high-quality service User-friendly online submission system Fair and swift peer-review system Efficient typesetting and proofreading procedure Display of the result of downloads and visits, as well as the number of cited articles Maximum dissemination of your research work

Submit your manuscript at: http://papersubmission.scirp.org/ Or contact ojmp@scirp.org 